УДК: 327

DOI 10.18413/2687-0967-2020-47-2-302-308

\title{
ПЕРСПЕКТИВЫ РОССИЙСКО-ЮЖНОКОРЕЙСКОГО СОТРУДНИЧЕСТВА В ОБЛАСТИ ОБРАЗОВАНИЯ В ХХІ ВЕКЕ
}

\section{PROSPECTS OF RUSSIAN AND SOUTH KOREAN COOPERATION IN THE EDUCATIONAL SPHERE IN THE XXI CENTURY}

\author{
И.В. Михайлов, М.И. Исмагилова \\ I.V. Mikhailov, M.I. Ismagilova \\ Тамбовский государственный университет им. Г.Р. Державина, \\ Российская Федерация, 392000, г. Тамбов, ул. Интернациональная, д. 33 \\ Tambov State University named after G.R. Derzhavin, \\ 33 Internationalnaya St, Tambov, 392000, Russian Federation \\ E-mail: m.i.v.2000@ mail.ru \\ E-mail:imi.me8@gmail.com
}

\begin{abstract}
Аннотация
Сотрудничество России и Южной Кореи является важной частью всей системы российскоюжнокорейских отношений. Республика Корея является одним из важных партнеров Российской Федерации в Азиатско-Тихоокеанском регионе. В настоящее время в Российской Федерации и Республики Корея достаточно большое количество школьников и студентов желают получить образование в странах-партнерах. В статье анализируется развитие российско-южнокорейского сотрудничества в сфере образования в XXI веке. Рассматриваются различные стипендиальные программы, разработанные правительствами России и Южной Кореи, а также ведущими российскими и южнокорейскими университетами, для привлечения иностранных студентов.
\end{abstract}

\begin{abstract}
Nowadays cooperation between Russia and South Korea is a significant part of the whole system of Russian and South Korean relationships. The Republic of Korea is one of the important partners of the Russian Federation in the Asia-Pacific region. Moreover, in the Russian Federation and the Republic of Korea there are a large amount of enrollees and students who would like to study in the partner countries. Based on these, this article reviews the development of Russian and South Korean cooperation in the educational sphere in the XXI century. The major goal of the study is the estimation of opportunities to study in the Russian Federation and the Republic of Korea. Based on these, in the present research paper the main attention is focused on various scholarship programs developed by the governments of Russia and South Korea and leading Russian and South Korean universities to attract foreign students. In the end of the study, the authors show advantages of partnership between the Russian Federation and the Republic of Korea.
\end{abstract}

Ключевые слова: поворот России на Восток, российско-южнокорейское сотрудничество, высшее образование, стипендиальные программы, «корейская волна», экзамены, высшие учебные заведения.

Keywords: Russia's turn to the East, Russian-South Korean cooperation, higher education, scholarship programs, «Korean wave», exams, universities.

Публикуется при грантовой поддержке Федерального агентства по делам молодежи, соглашение № 091-15-2019-104 от 04.09.2019. 
Поворот России на Восток, о котором в последнее время говорят политики, политологи и экономисты, становится все более актуальной повесткой дня российской внешней политики. Тема Востока, в частности, стала главной на XVI заседании Международного дискуссионного клуба «Валдай», членами которого являются ведущие российские и иностранные специалисты в области международных отношений. В пленарной сессии принял участие Президент Российской Федерации В.В. Путин, который подчеркнул усиление роли азиатских государств в мировых делах. «Укрепление позиций азиатских государств заметно во всех сферах, - отметил российский Президент. - .. В регионе уже формируется более трети мирового валового продукта. Опережая среднемировые темпы, повышается и уровень жизни. Активно внедряются самые передовые технологии. Беспрецедентные по охвату интеграционные процессы, глобализация буквально притягивают к Азии как отдельных внешних игроков, так и целые сопредельные субрегионы» [Заседание дискуссионного клуба «Валдай» (вебсайт)].

Пристальное внимание России к Востоку требует укрепления политических, экономических и культурных связей со странами региона. Нашей стране требуется все больше специалистов, понимающих как общую цивилизационную специфику, так и отличительные особенности азиатских народов. Россия заинтересована не только в завоевании перспективных азиатских рынков, она стремится к улучшению своего положительного имиджа в мире, чему во многом способствует трансляция российских достижений в различных областях деятельности на страны Востока. Очевидно, что одним из направлений, содействующих решению данных задач, является сотрудничество с азиатскими государствами в области образования. Студенческий обмен, прохождение программ бакалавриата или магистратуры в другой стране - достаточно распространенные практики на сегодняшний день. Современная молодежь понимает, что во многом именно хорошее образование является тем социальным лифтом, который дает возможности для достижения успеха в различных сферах деятельности.

В контексте «поворота России на Восток» Республика Корея является одним из приоритетных партнеров Российской Федерации в Азиатско-Тихоокеанском регионе. Развивается и сотрудничество в области образования между нашими странами. Этому способствует установление в 2014 г. безвизового режима между Россией и Южной Кореей, вследствие чего российские и южнокорейские граждане могут находиться на территории стран-партнеров в течение 90 дней без получения визы [Иммиграционная служба Республики Корея (вебсайт)]. Благодаря развивающемуся российско-корейскому сотрудничеству граждане Южной Кореи имеют возможность продолжить свое обучение в высших учебных заведениях Российской Федерации, а российские студенты, соответственно, в университетах Республики Корея. Российские и южнокорейские дипломы о получении высшего образования принимаются во всем мире. При поступлении иностранных абитуриентов в университеты России и Южной Кореи проводится равный конкурсный отбор, независимо от того, из какой страны приехал студент.

Российская Федерация - один из мировых лидеров в области информационных технологий, финансовых услуг, медицины, в космической и атомной отраслях. При этом стоимость высшего образования в России в 5-7 раз ниже, чем в странах Европы. По данным Института статистики ЮНЕСКО (United Nations Educational, Scientific and Cultural Organization), Россия занимает шестое место в мире по привлекательности для иностранных студентов после Соединенных Штатов Америки (США), Великобритании, Австралии, Франции и Германии [UIS Statistic (вебсайт)]. 25 российских университетов вошли в рейтинг британского исследовательского центра Quacquarelli Symonds (QS) 2020 года [QS World University Rankings (вебсайт)]. Более чем половине из них удалось улучшить свои позиции по сравнению с прошлым годом [QS World University Rankings (вебсайт)]. По версии Quacquarelli Symonds, лучшим российским университетом является Московский государственный университет имени М.В. Ломоносова (МГУ) (84 место) [Московский государственный университет имени М.В. Ломоносова (вебсайт)]. На втором месте Новосибирский государственный университет (231 место). Кроме этого, в список Quacquarelli 
Symonds вошли: Московский физико-технический институт (302 место); Национальный исследовательский университет «Высшая школа экономики» (322 место); Уральский федеральный университет (364 место).

При поступлении в российские университеты корейским абитуриентам нужно сдать экзамен по русскому языку. Если абитуриент не в достаточной мере владеет русским языком, он проходит языковые курсы при университете, в который планирует поступить. Длительность таких курсов составляет примерно один год. Также существуют летние и зимние школы русского языка, где обучение длится от 3 недель до 3 месяцев [Russia.Study (вебсайт)]. Южнокорейские граждане могут изучать русский язык при посольстве Российской Федерации в Республике Корея [Посольство Российской Федерации в Республике Корея (вебсайт)].

Граждане Южной Кореи, желающие продолжить свое образование в России, поступают в российские университеты преимущественно на платной основе. Однако для абитуриентов, не имеющих такой возможности, была создана «Государственная стипендия». Данная программа предоставляет бесплатное обучение в университете и ежемесячную стипендию [Russia.Study (вебсайт)].

По данным сайта Russia.Study, количество южнокорейских студентов, получающих сегодня высшее образование в России, невелико и явно уступает потоку студентов из других восточноазиатских государств, таких как Китай, Вьетнам, Монголия, а также арабских и африканских стран [Russia.Study (вебсайт)]. Этот факт не вызывает особого оптимизма, но и не слишком пессимистичен. Ведь именно здесь во многом и лежат возможности роста сотрудничества между Российской Федерацией и Республикой Корея в области образования. В июне 2017 г. Правительством Российской Федерации был утвержден Паспорт приоритетного проекта «Развитие экспортного потенциала российской системы образования». Согласно этому документу в результате реализации проекта, который направлен на «привлекательность и конкурентоспособность российского образования на международном рынке образовательных услуг», «количество иностранных студентов, которые обучаются по очной форме в российских вузах, должно вырасти с 220 тыс. чел. в 2017 г. до 710 тыс. в 2025 г., а количество иностранных слушателей онлайн-курсов российских образовательных организаций - с 1 млн 100 тыс. чел. до 3 млн 500 тыс. чел.» [Развитие экспортного потенциала российской системы образования (вебсайт)].

В начале XXI века мир накрыла «корейская волна». Это было обусловлено большой популярностью корейской музыки, моды, кинофильмов. Но «корейская волна» связана не только с популярностью южнокорейской культуры. Корейская экономика демонстрировала высокий рост [Михайлик, 2008, с. 32]. В 2019 г. (шестой год подряд) экономика Южной Кореи признана самой инновационной экономикой мира [Самые инновационные экономики мира - 2019 (вебсайт)]. Она оставила позади себя по этому показателю такие высокоразвитые экономики мира, как экономики Германии, Финляндии, Швейцарии, Израиля, Сингапура, Швеции, США, Японии и Франции. При составлении рейтинга учитывались следующие показатели: интенсивность научных исследований и разработок, добавленная стоимость в производстве, производительность труда, удельный вес высоких технологий, количество специалистов, участвующих в исследованиях, патентная активность. Также, на что следует обратить особое внимание, одним из важных факторов, влияющих на создание инновационной экономики, является «эффективность высшего образования» [Самые инновационные экономики мира - 2019 (вебсайт)].

Под влиянием «корейской волны» достаточно большое количество российских студентов стремятся посетить Южную Корею, изучить культуру, выучить язык и продолжить свое образование в корейских университетах. Система образования Республики Корея сходна с системой образования США, Великобритании и континентальной Европы. Она полностью отвечает требованиям Болонской системы - бакалавриат (4 года), магистратура (2 года), докторантура (3 года). Вместе с этим есть и свои особенности. Учебный год в Южной Корее стандартно делится на 2 семестра. Но первый начинается в марте и заканчивается в середине 
июля, а второй длится с сентября по декабрь. Каникулы у студентов проходят между концом одного семестра и началом другого [Очирова, 2015, с. 65].

В 1997 г. в Республике Корея был принят закон, согласно которому высшие учебные заведения страны делятся на 4 категории: колледжи и университеты; педагогические колледжи; университеты с заочной формой обучения; богословские колледжи, семинарии [Gwang-Jo Kim, p. 33]. В настоящее время в Республике Корея существует примерно 400 университетов [Study in Korea (вебсайт)].

Тройку самых лучших вузов страны составляют: Сеульский национальный университет (Seoul National University), Университет Ёнсе (Yonsei University) и Университет Коpë (Korea Advanced Institute of Science and Technology). Они также входят в топ двадцать лучших азиатских университетов [Asia University Rankings 2019 (вебсайт)].

Сеульский национальный университет - самый крупный и престижный университет в Республике Корея. Он был основан в конце XIX в. при императоре Кореи Коджоне. Факультеты технических и естественных наук имеют высокий рейтинг во всем мире [QS World University Rankings (вебсайт)]. Большая часть южнокорейских чиновников являются выпускниками этого института. Данный университет сотрудничает с более чем 800 высшими учебными заведениями по всему миру и ведет программу обучения по студенческому обмену.

Университет Корё (Корейский ведущий научно-технический институт) занимает второе место по качеству образования в Южной Корее. Он был основан в 1971 г. для развития науки и техники в стране [Университет Корё (вебсайт)].

Университет Ёнсе - также престижное корейское высшее учебное заведение. Он был основан в 1885 г. Программа по студенческому обмену достаточно хорошо развита. Данный университет сотрудничает с тремя российскими вузами: Санкт-Петербургским государственным университетом, Московским государственным университетом и Дальневосточный федеральным университетом [Университет Ёнсе (вебсайт)].

Студенты из России, желающие получить высшее образование в Южной Корее, могут поступить в университет страны только при условии, что предварительно пройдут годовой курс по изучению корейского языка. При условии того, что студент уже владеет корейским языком, он должен предоставить сертификат международного экзамена «TOPIK» («Test of Proficiency in Korean»). Для поступления в южнокорейские институты российский абитуриент должен иметь законченное среднее полное образование или же среднее профессиональное образование. Обучение в корейских университетах идет на корейском и английском языках, так как там работает большое количество иностранных преподавателей.

Граждане России, желающие изучать корейский язык и культуру на бесплатной основе, могут посещать Корейский культурный центр при посольстве Республики Корея в Москве [Корейский культурный центр при посольстве Республики Корея в Москве (вебсайт)]. На сайте Министерства иностранных дел Южной Кореи размещена подробная информация [Министерство иностранных дел Республики Корея (вебсайт)]. Кроме этого, российские абитуриенты могут посещать платные языковые школы с различными языковыми и культурными программами в корейских университетах. Обучение в таких школах длится от 3 до 10 недель. Так, например, в университетах Корё и Ёнсе работают Международные Летние школы, целью которых, как сказано на сайте университета, «является привлечение иностранных студентов для культурного обмена, расширения кругозора и обретения новых друзей из разных стран» [Университет Ёнсе (вебсайт)].

Граждане Российской Федерации могут претендовать на обучение в Республике Корея и по стипендиальной программе. Правительство Южной Кореи разработало различные образовательные программы, позволяющие иностранным гражданам продолжить свое обучение в этом государстве. Однако для того, чтобы выдвинуть свою кандидатуру на получение стипендии, абитуриент должен владеть корейским языком не ниже третьего уровня, согласно требованиям «TOPIK» («Test of Proficiency in Korean»), а для студентов магистратуры - не ниже пятого уровня [Test of Proficiency in Korean (вебсайт)]. Кроме того, нужно иметь сертификат TOEFL 
(Test of English as a Foreign Language) или IELTS (International English Language Testing System) о владении и сдаче международного экзамена по английскому языку.

Самой популярной стипендиальной программой является «Стипендиальная Программа Корейского Правительства» («Korean Government Scholarship Program») [(вебсайт)]. Цель программы - предоставить иностранным студентам возможности обучения по программам бакалавриата и магистратуры в высших учебных заведениях Республики Корея и посредством этого укреплять отношения с различными государствами мира. Денежное пособие включает перелет в оба конца (но только один раз), оплату обучения и годового курса корейского языка, ежемесячную стипендию в размере 800000 вон (примерно 45000 рублей) обучающимся по программе бакалавриата и 900000 вон (приблизительно 50000 рублей) обучающимся по программе магистратуры и медицинскую страховку [Сеульский национальный университет (вебсайт)].

Еще одна популярная правительственная программа «Программа правительства Кореи для студентов из стран-партнеров» («Korean Government Invitation Program for Students from Partner Countries»). Эта программа является краткосрочной и проходит на английском языке. Стать ее стипендиатами приглашаются иностранные студенты, ведущие активную общественную жизнь и стремящиеся стать лидерами в своих странах. В программу включены: лекции по истории, экономике и культуре; тур по университетам и историческим местам Республики Корея. Организаторы оплачивают билеты на самолет, проживание и страховку [Министерство иностранных дел Республики Корея (вебсайт)].

Российские граждане могут и самостоятельно поступать в южнокорейские вузы на платной основе. При этом абитуриент может получить 70 \% скидку на обучение, если представит портфолио, показывающее его достижения в различных областях деятельности (дипломы, участие в международных конференциях, волонтерство, публикации и т. д.), и это будет оценено приемной комиссии [Study in Korea (вебсайт)]. Наряду с этим существует также «Программа поддержки для студентов, финансируемых за счет собственных средств» («Support Program for Self-financed Students») [Министерство иностранных дел Республики Корея (вебсайт)]. Целью данной стипендии является оказание материальной поддержки отличившихся в учебе студентов. Она предоставляется студентам, обучающимся в университете Южной Кореи не менее двух семестров и с баллом за успеваемость более 80 \%. Также учащийся должен иметь 4 уровень знания корейского языка по ТОРІС.

Существует еще одна программа - «Программа приглашения правительством Кореи студентов из стран-партнеров» («Korean Government Invitation Program for Students from Partner Countries»). Она является краткосрочной и проходит на английском языке. Стать участниками данной программы приглашаются иностранные студенты, которые могут стать лидерами в разных сферах деятельности в своих странах, чтобы углубить свое понимание Южной Кореи и обеспечить мотивацию обучения в Корее для будущего поколения [Министерство иностранных дел Республики Корея (вебсайт)]. В программу включены: лекции по истории, экономике и культуре; тур по университетам и историческим местам Республики Корея. Организаторы оплачивают билеты на самолет, проживание и страховку.

Корейские высшие учебные заведения создают и собственные стипендиальные программы. Так, например, университет Корё предоставляет «Global Korea University Study Abroad». Данная стипендия бывает трех видов: 1) с 1 курса в каждом семестре выплачивается по 400000 вон (примерно 21500 рублей); 2) единоразовое начисление стипендии в размере 1500000 вон (примерно 80500 рублей); 3) ежемесячная стипендия за учебные достижения в размере 300000 вон (приблизительно 16000 рублей). В программе могут участвовать студенты, уже обучающиеся в корейском университете, или же студенты по обмену, желающие продолжить свое образование в Южной Корее. Стипендия оплачивает либо 50 \% стоимости обучения, либо $100 \%$, в зависимости от уровня успеваемости учащегося [Университет Корё (вебсайт)].

Таким образом, можно сделать вывод о том, что на сегодняшний день существует достаточно большое количество программ и стипендий как в Российской Федерации, так 
и в Республике Корея, направленных на взаимное привлечение иностранных студентов. Это правительственные и университетские гранты, а также возможность проходить обучение за счет своих собственных средств. Эти возможности активно используют российские и корейские студенты. Но очевидно, что потенциал сотрудничества между нашими странами в области образования этим не исчерпывается. Создание специальных курсов, увеличение грантовой поддержки, расширение количества вузов, участвующих в программах обмена, - вот «точки роста» российско-южнокорейского сотрудничества в области образования в XXI веке.

\section{Список литературы}

1. Заседание дискуссионного клуба «Валдай» [вебсайт]. URL: http://www.kremlin.ru/events/president/news/61719 (Дата обращения 28.11.2019).

2. Корейский культурный центр при посольстве Республики Корея в Москве [вебсайт]. URL: http://russia.korean-culture.org/ru (Дата обращения 28.11.2019).

3. Михайлик О.Н. 2008. Феномен «корейской волны»: синтез Запада и Востока? Известия Иркутского государственного университета. Серия: Политология. Религиоведение: 31-40.

4. Московский государственный университет имени M.B. Ломоносова [вебсайт]. URL: https://www.msu.ru/ (Дата обращения 28.11.2019).

5. Очирова Д.Б. 2015. Система высшего образования в Республике Корея: история и современное состояние. Образование. Личность. Общество: 64-67.

6. Посольство Российской Федерации в Республике Корея [вебсайт]. URL: https://koreaseoul.mid.ru/embassy (Дата обращения 28.11.2019).

7. Развитие экспортного потенциала российской системы образования [вебсайт]. URL: http://government.ru/news/28013/ (Дата обращения 28.11.2019).

8. Самые инновационные экономики мира - 2019 [вебсайт]. URL: http://globalfinances.ru/bloomberg-innovation-index-2019/ (Дата обращения 28.11.2019).

$\begin{array}{lllll}\text { 9. Asia University } & \text { Rankings } & 2019 & \text { Uвебсайт]. }\end{array}$ https://www.timeshighereducation.com/world-university-rankings/2019/regional-ranking (Дата обращения 28.11.2019).

10. Gwang-Jo Kim. Education Policies and Reform in South Korea [вебсайт]. URL: https://pdfs.semanticscholar.org/465c/225a7070d9ff272b0d4c7be8858c00044617.pdf (Дата обращения 28.11.2019).

11. Immigration Service of the Republic of Korea [вебсайт]. URL: https://www.visa.go.kr/ (Дата обращения 28.11.2019).

12. Korea Advanced Institute of Science and Technology [вебсайт]. URL: https://www.kaist.ac.kr/html/en/ (Дата обращения 28.11.2019).

13. Ministry of Foreign Affairs of the Republic of Korea [вебсайт]. URL: http://www.mofa.go.kr/www/index.do (Дата обращения 28.11.2019).

14. QS World University Rankings [вебсайт]. URL: https://www.topuniversities.com/universityrankings/asian-university-rankings/2020 (Дата обращения 28.11.2019).

15. Russia.Study [вебсайт]. URL: https://russia.study/ru (Дата обращения 28.11.2019).

16. Seoul National University [вебсайт]. URL: http://snu.ac.kr/index.html (Дата обращения 28.11.2019).

17. Study in Korea [вебсайт]. URL: http://studyinkorea.go.kr/en/main.do;jsessionid=E38B4FCD68AA76E244567C782EA02C84.node_10 (Дата обращения 28.11.2019).

18. Test of Proficiency in Korean [вебсайт]. URL: http://www.topik.go.kr/usr/cmm/index.do (Дата обращения 28.11.2019). 28.11.2019).

19. UIS Statistic [вебсайт]. URL: http://data.uis.unesco.org/Index.aspx (Дата обращения

20. Yonsei University [вебсайт]. URL: https://www.yonsei.ac.kr/en_sc/index.jsp (Дата обращения 28.11.2019). 


\section{Referenses}

1. Zasedanie diskussionnogo kluba «Valdaj» [Meeting of the Valdai Discussion Club] [вебсайт]. URL: http://www.kremlin.ru/events/president/news/61719 (Дата обращения 28.11.2019) (in Russian).

2. Korejskij kul'turnyj centr pri posol'stve Respubliki Koreya v Moskve [Korean Cultural Center at the Embassy of the Republic of Korea in Moscow] [вебсайт]. URL: http://russia.korean-culture.org/ru (Дата обращения 28.11.2019) (in Russian).

3. Mikhailik O.N. 2008. Fenomen «korejskoj volny»: sintez Zapada i Vostoka? [The phenomenon of the «Korean wave»: a synthesis of West and East?] Izvestiya Irkutskogo gosudarstvennogo universiteta. Seriya: Politologiya. Religiovedenie [Bulletin of Irkutsk State University. Series: Political Science. Religious studies]: 31-40 (in Russian).

4. Moscow State University named after M.V. Lomonosov [вебсайт]. URL: https://www.msu.ru/ (Дата обращения 28.11.2019) (in Russian).

5. Ochirova D.B. 2015. Sistema vysshego obrazovaniya v Respublike Koreya: istoriya i sovremennoe sostoyanie [The system of higher education in the Republic of Korea: history and current status]. Obrazovanie. Lichnost'. Obshchestvo [Education. Personality. Society]: 64-67.

6. Embassy of the Russian Federation in the Republic of Korea [вебсайт]. URL: https://koreaseoul.mid.ru/embassy (Дата обращения 28.11.2019) (in Russian).

7. Development of the export potential of the Russian education system [вебсайт]. URL: http://government.ru/news/28013/ (Дата обращения 28.11.2019) (in Russian).

8. The most innovative economies in the world - 2019 [вебсайт]. URL: http://globalfinances.ru/bloomberg-innovation-index-2019/ (Дата обращения 28.11.2019) (in Russian).

9. Asia University Rankings 2019 [вебсайт]. URL: https://www.timeshighereducation.com/world-university-rankings/2019/regional-ranking (Дата обращения 28.11.2019).

10. Gwang-Jo Kim. Education Policies and Reform in South Korea [вебсайт]. URL: https://pdfs.semanticscholar.org/465c/225a7070d9ff272b0d4c7be8858c00044617.pdf (Дата обращения 28.11.2019).

11. Immigration Service of the Republic of Korea [вебсайт]. URL: https://www.visa.go.kr/ (Дата обращения 28.11.2019).

12. Korea Advanced Institute of Science and Technology [вебсайт]. URL: https://www.kaist.ac.kr/html/en/ (Дата обращения 28.11.2019).

13. Ministry of Foreign Affairs of the Republic of Korea [вебсайт]. URL: http://www.mofa.go.kr/www/index.do (Дата обращения 28.11.2019).

14. QS World University Rankings [вебсайт]. URL: https://www.topuniversities.com/universityrankings/asian-university-rankings/2020 (Дата обращения 28.11.2019).

15. Russia.Study [вебсайт]. URL: https://russia.study/ru (Дата обращения 28.11.2019).

16. Seoul National University [вебсайт]. URL: http://snu.ac.kr/index.html (Дата обращения 28.11.2019).

17. Study in Korea [вебсайт]. URL:
[в http://studyinkorea.go.kr/en/main.do;jsessionid=E38B4FCD68AA76E244567C782EA02C84.node_10 (Дата обращения 28.11.2019).

18. Test of Proficiency in Korean [вебсайт]. URL: http://www.topik.go.kr/usr/cmm/index.do (Дата обращения 28.11.2019).

19. UIS Statistic [вебсайт]. URL: http://data.uis.unesco.org/Index.aspx (Дата обращения 28.11.2019).

20. Yonsei University [вебсайт]. URL: https://www.yonsei.ac.kr/en_sc/index.jsp (Дата обращения 28.11.2019).

\section{Ссылка для цитирования статьи Link for article citation}

Михайлов И.В., Исмагилова М.И. 2020. Перспективы российско-южнокорейского сотрудничества в области образования в XXI веке. Via in tempore. История. Политология, 47 (2): 302-308. DOI 10.18413/2687-0967-2020-47-2-302-308.

Mikhailov I.V., Ismagilova M.I. 2020. Prospects of Russian and South Korean cooperation in the educational sphere in the XXI century. Via in tempore. History and political science, 47 (2): 302-308 (in Russian). DOI 10.18413/2687-0967-2020-47-2-302-308. 